\title{
Estimation of improved resolution soil moisture in vegetated areas using passive AMSR-E data
}

\author{
Mina Moradizadeh ${ }^{1} *$ and Mohammad R Saradjian ${ }^{2}$ \\ ${ }^{1}$ Department of Geomatics, Faculty of Civil and Transportation Engineering, University of Isfahan, Isfahan, Iran. \\ ${ }^{2}$ Remote Sensing Division, School of Surveying and Geospatial Engineering, College of Engineering, University of \\ Tehran, Tehran, Iran. \\ *Corresponding author.e-mail: mina_moradizadeh@yahoo.com
}

MS received 9 February 2016; revised 16 March 2017; accepted 31 July 2017; published online 6 March 2018

Microwave remote sensing provides a unique capability for soil parameter retrievals. Therefore, various soil parameters estimation models have been developed using brightness temperature (BT) measured by passive microwave sensors. Due to the low resolution of satellite microwave radiometer data, the main goal of this study is to develop a downscaling approach to improve the spatial resolution of soil moisture estimates with the use of higher resolution visible/infrared sensor data. Accordingly, after the soil parameters have been obtained using Simultaneous Land Parameters Retrieval Model algorithm, the downscaling method has been applied to the soil moisture estimations that have been validated against in situ soil moisture data. Advance Microwave Scanning Radiometer-EOS BT data in Soil Moisture Experiment 2003 region in the south and north of Oklahoma have been used to this end. Results illustrated that the soil moisture variability is effectively captured at $5 \mathrm{~km}$ spatial scales without a significant degradation of the accuracy.

Keywords. Soil moisture; land surface parameters; SLPRM; AMSR-E; downscaling; MODIS.

\section{Introduction}

For the purpose of large scale climate modelling and monitoring, circulation process, weather prediction, flood forecasting and drought monitoring regarding agricultural activities, there is an increasing demand for global and spatially averaged surface soil moisture data (Schar et al. 1999; Owe et al. 2001; Seneviratne et al. 2006; Doubkova et al. 2012). Therefore, studies on soil moisture monitoring through remote sensing in wide areas have made great progress (Owe et al. 2001; Srivastava et al. 2009; Saradjian and Hosseini 2011; Doubkova et al. 2012; Pan et al. 2014; Singh et al. 2015b; Zheng et al. 2015).
It is evident that there are large number of factors such as soil moisture, soil temperature, vegetation characters and surface roughness along with soil texture affecting the emission process. Therefore, the absolute magnitude of the soil reflectivity, emissivity and brightness temperature are affected by these factors, especially in the soilvegetation medium (Owe et al. 1992; Njoku and Chan 2006). However, the effect of atmosphere is negligible at frequencies below $10 \mathrm{GHz}$ (Schmugge 1985).

These perturbing factors introduce varying amounts of uncertainty into soil moisture estimation from BT data. They are typically required to model radiative transfer in all regions except 
for regions of water and snow cover (Tsang and Newton 1982; Ulaby et al. 1983; Dobson et al. 1985; Pampaloni and Paloscia 1986; Mo et al. 1987; Jackson and Schmugge 1991; Njoku 1995; Njoku and Chan 2006; Colliander et al. 2012). On the other hand, the characteristics of passive microwave remote sensing have long been recognized and various methodologies have been described to obtain surface soil characteristics accordingly (Jackson 1993; Wigneron et al. 1995; Njoku and Li 1999; Chanzy and Wigneron 2000; Owe et al. 2001). Therefore, in order to obtain accurate soil moisture estimates by means of remote sensing technology, retrieving multiple land surface parameters using passive microwave remote sensing observations has become a research focus.

There are large number of models that retrieve soil parameters by the use of passive microwave and Singh et al. (2015a) provided detailed procedure of various steps to utilize AMSR-E data.

Using microwaves, linear regression methods have been mainly used in the past for retrieving land surface parameters. Non-linear and iterative algorithms have also been used, particularly to improve retrievals in which the physical properties of the radiative transfer and interaction process are non-linear (Li et al. 2011).

In most of the models, vegetation and roughness effects have not been modelled properly (Owe et al. 2001; Njoku and Chan 2006; Li et al. 2011). However, there are some models in which both roughness and vegetation effects have been considered (Wigneron et al. 2007; Patel and Srivastava 2015).

Therefore, SLPRM algorithm has been developed by Moradizadeh and Saradjian (2016). This algorithm estimates surface volumetric soil moisture (VSM), land surface temperature (LST) and canopy temperature (CT) simultaneously, whereas the roughness and vegetation effects have also been modelled.

In this study, due to the low resolution of satellite microwave radiometer data, a downscaling method has been applied to the soil moisture estimations that have been validated against in situ soil moisture data.

It is worth noting that AMSR-E C-band (6.9 $\mathrm{GHz}$ ) brightness temperature data are subjected to radio frequency interference (RFI; Jackson et al. 2005). Therefore, combination of C, X (10.65 GHz) and $\mathrm{K}(18.7 \mathrm{GHz})$ bands $\mathrm{BT}$ observation in SLPRM model is effective to decrease the RFI contamination.
This paper is organized as follows: the study region and the data used are described in section 2 . In section 3, the proposed method to estimate soil moisture is presented. Section 4 describes the results and discussion of soil moisture estimates obtained using the model. Section 5 summarizes and concludes the paper.

\section{Study area and datasets}

\subsection{Study region}

During the soil moisture experiment in summer 2003 (SMEX03), there were combined objectives with ground/aircraft/spacecraft observations over sites in Oklahoma, Georgia, Alabama, and Brazil. These datasets made it possible to study the different behaviors of brightness temperature above bare soil and vegetated areas.

In order to perform calibration and validation of the downscaling method, parts of the observations in SMEX03 have been used in this study.

The study area is composed of two regions, OS and ON, located in the south and north of Oklahoma, USA, respectively. More details about the regions can be found in the report provided by Allen and Naney (1991). Geographic locations of the two study regions and ground sites in the north and south of Oklahoma are shown in figure 1.
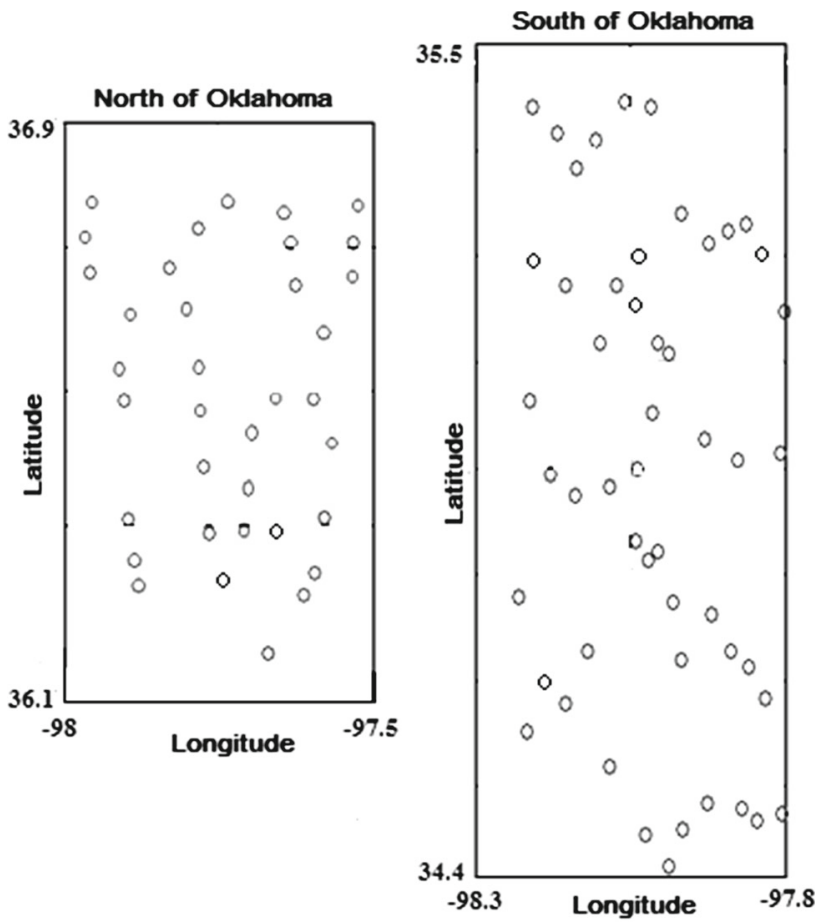

Figure 1. Thirty six and 52 ground sites in the north and south of Oklahoma, respectively. 


\subsection{Ground truth datasets}

\subsubsection{VSM, LST and bulk density datasets}

The SMEX03 dataset collected on 2, 3 and 4 July, 2003 have been used in this study. There are many sites in the SMEX03 region, where the volumetric soil moisture (VSM), LST and bulk density (Bd) at different depths have been measured. The total number of sites used as samples is 88 per day. The number of sites in OS is 52 and in ON is 36 (Moradizadeh and Saradjian 2016). Regarding the potential of the proposed algorithm, all sites with various vegetation densities and soil moisture content have been selected for calibration and validation purposes.

The set of experimental data can be downloaded freely from http://nsidc.org/data/amsr_validation /soil_moisture/smex03/index.html.

\subsubsection{Roughness dataset}

The soil surface roughness parameter including root mean square height $(\sigma)$ per correlation length $(l)$ was extracted from SMEX03 datasets. The $\sigma$ parameter describes the random surface characteristics, while the $l$ parameter describes the periodicity of the surface.

\subsection{Satellite datasets}

\subsubsection{AMSR-E datasets}

The study was conducted using AMSR-E microwave datasets, registered on 2, 3 and 4 July, 2003 on the selected region. Selection of these days is simply because of the possibility of analysis due to the ground measurements made on these days.

AMSR-E flew onboard the NASA's Aqua satellite since 2002. It measures horizontally and vertically polarized brightness temperatures at 6.9 , $10.7,18.7,23.8,36.5$ and $89.0 \mathrm{GHz}$. It is characterized by a coarse spatial resolution varying from $5.4 \mathrm{~km}$ at $89.0 \mathrm{GHz}$ to $56 \mathrm{~km}$ at $6.9 \mathrm{GHz}$ (Njoku et al. 2003; Walker and Houser 2004; Njoku and Chan 2006; De Lange et al. 2008).

Only day time AMSR-E data have been used in this study because the SMEX03 ground data have been observed around noon and are more likely to be true at 1:30 P.M. than at 1:30 A.M.

\subsubsection{MODIS datasets}

The MODIS spectrometer with its 36 bands is operational on both Terra (10:30 A.M./10:30 P.M.) and Aqua (1:30 A.M./1:30 P.M.) spacecrafts. The MODIS data used in this study are the daily (ascending) MODIS/Aqua $1 \mathrm{~km}$ resolution acquired on 2, 3 and 4 July 2003. MODIS data have been selected among other operational Vis/IR sensors because both MODIS and AMSR-E are onboard the Aqua satellite.

The useful characteristics of this sensor are mainly its 1-2 days temporal resolution, near realtime data availability, $1 \mathrm{~km}$ spatial resolution, and overpass time compatibility required for downscaling.

\section{Modelling approach}

\subsection{Simultaneous estimation of soil moisture, LST, and canopy temperature}

SLPRM algorithm that is an iterative least-square minimization algorithm is applied to simultaneous retrieval of soil moisture, LST and canopy temperature by using multichannel microwave measurements. Therefore, initial values of soil parameters (i.e., VSM, LST and bulk density) are required. Although, according to our experiments, the results are not greatly affected by initial values, rather these values are obtained based on their average amounts in the region in this study. For further clarification and ease of understanding, the flowchart of the SLPRM model is presented in figure 2 .

In this figure, $\varepsilon, \Theta$ and $P$ are dielectric constant, incidence angle and polarization, respectively. Effective land surface reflectivity, effective emissivity and effective temperature are shown using $R_{P}(\theta), E_{P}(\theta)$ and $T$. Furthermore, $\Gamma$ is vegetation transmissivity that is defined in terms of a vegetation index and incidence angle.

This SLPRM algorithm simultaneously retrieves $M$ geophysical variables (soil moisture (VSM), surface temperature (LST) and canopy temperature (CT)) from measurements at $N$ channels, which refers to the six lower frequency channels of AMSR-E (i.e., 6.9, 10.65, $18.7 \mathrm{GHz}$ in $H$ and $V$ polarizations) and are more sensitive to soil parameters especially soil moisture. The procedure operates based on least square error minimization method and finds such values for the set of variables $\chi=\left\{V S M, L S T, T_{s}\right\}$ that minimizes $\chi^{2}$. 


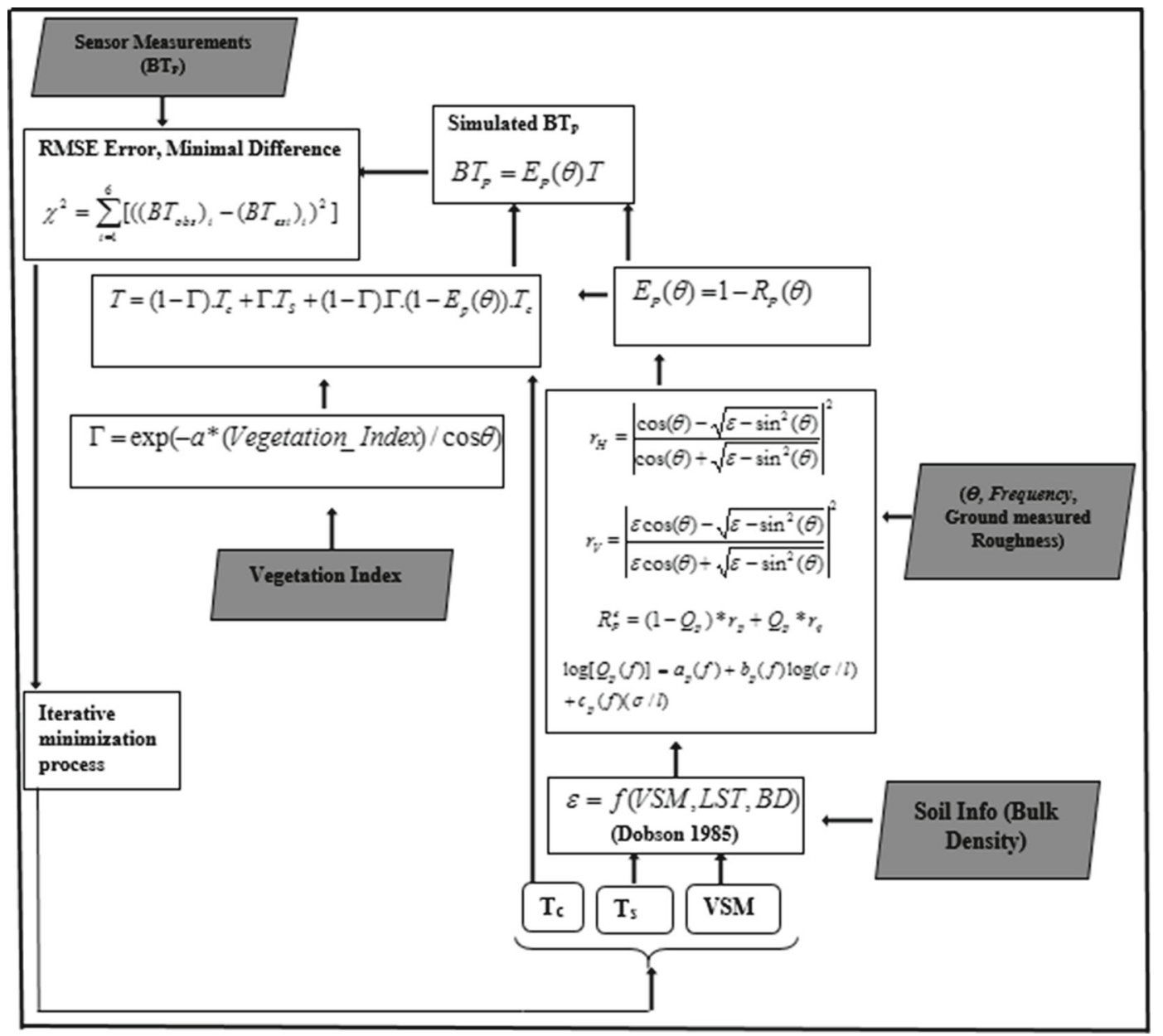

Figure 2. The graphical presentation of the SLPRM model.

More details about the SLPRM algorithm can be found in Moradizadeh and Saradjian (2016).

The use of this method usually requires an accurate roughness condition, especially when dealing with the bare soil surface or surface with low vegetation.

Note that some of the symbols and basic equations in figure 2 can be found in Owe et al. (2001) and Li et al. (2011).

\subsection{Soil moisture downscaling}

The results of previous studies have acknowledged the ability of Vis/IR sensors in soil moisture sensing and showed reasonable agreement with ground data (Wang et al. 2007; Piles et al. 2010). They normally have suitable resolution, however, soil moisture estimate from those sensors usually requires surface micro-meteorological and atmospheric information that is not routinely available (Zhang and Wegehenkel 2006). Because of the microwave capability for direct observation of soil moisture, combination of Vis/IR and microwave sensors can be used to achieve both accurate and higher spatial resolution soil moisture.

In order to improve the spatial resolution of derived soil moisture estimates, MODIS data has been selected among other operational Vis/IR sensors. Both MODIS and AMSR-E are onboard the Aqua satellite (1:30 A.M./1:30 P.M.). Thus, the same overpass time of the two sensors is the actual reason for MODIS selection. Following the soil estimation, a downscaling method using MODISderived NDVI (Normalized Difference Vegetation Index) and Ts data has been developed to improve the spatial resolution of derived soil moisture estimates.

To relate retrieved soil moisture amounts to MODIS-derived NDVI and LST, a linking model based on the so-called 'universal triangle' concept has been developed (Carlson 2007). The use of MODIS Vis/IR data for downscaling AMSR$\mathrm{E}$ derived soil moisture has some limitations that difference in sensing depth is the most effective 
limitation. The other limitation is that microwave band can penetrate vegetated regions but thermal infrared cannot. The sensing depth of AMSR-E bands is about $5 \mathrm{~cm}$, whereas for the MODIS thermal infrared band is about $1 \mathrm{~mm}$ and the thermal regime of these two depths can be quite different from each other (Piles et al. 2011).

Since MODIS is not capable to displaying spatial and temporal variations of $0-5 \mathrm{~cm}$ soil temperature, AMSR-E brightness temperature (TB) has been included to the linking model of downscaling algorithm to capture soil moisture variability at high resolution (Piles et al. 2011). In addition to the soil moisture, TB includes information about soil roughness, soil texture, soil temperature and vegetation.

The linking model can be expressed using a regression in the form of equation (1). This equation is used to set up a system of linear equations for all the pixels in the image, which gives regression coefficients $a_{i}$ (Piles et al. 2011)

$$
\begin{aligned}
S M= & a_{0}+a_{1} T_{B N}+a_{2} T_{N}+a_{3} F_{r} \\
& +a_{4} T_{B N}^{2}+a_{5} T_{N}^{2}+a_{6} F_{r}^{2} \\
& +a_{7} T_{N} T_{B N}+a_{8} F_{r} T_{B N}+a_{9} F_{r} T_{N}
\end{aligned}
$$

where $T_{N}$ is normalized surface radiant temperature, $F_{r}$ is the fractional vegetation cover (Gutman and Ignatov 1998) and $T_{B N}$ are the normalized AMSR-E brightness defined as:

$$
\begin{aligned}
T_{N} & =\frac{T_{S}-T_{\min }}{T_{\max }-T_{\min }} \\
F_{r} & =\frac{N D V I-N D V I_{\min }}{N D V I_{\max }-N D V I_{\min }} \\
T_{B N} & =\frac{T B-T B_{\min }}{T B_{\max }-T B_{\min }}
\end{aligned}
$$

$T_{\max }, T_{\min }, N D V I_{\max }$ and $N D V I_{\min }$ are the maximum and minimum LST and NDVI values for a particular day and region under study. Normalization is needed to reduce the dependence of LST and NDVI on ambient conditions, and to allow further comparison of different experiments (Piles et al. 2011).

\section{Implementation}

In order to estimate soil moisture, LST and canopy temperature simultaneously, the SLPRM method has been applied to the AMSR-E brightness temperatures for $\mathrm{ON}$ and $\mathrm{OS}$ on 2, 3 and 4 July, 2003. Also, in order to perform downscaling, the NDVI values have been calculated using MODIS bands 1 and 2 and the LST values have been estimated using MODIS bands 31 and 32, which were acquired on 2, 3 and 4 July, 2003 (Moradizadeh et al. 2013, 2017). Then, equation (1) has been applied using the regression coefficients, $T_{N}$ and $F_{r}$ aggregated to $5 \mathrm{~km}$, and AMSR-E $T_{B N}$ resampled to a $5 \times 5 \mathrm{~km}$ grid. As a result, soil moisture map with higher spatial resolution at $5 \mathrm{~km}$ instead of $25 \mathrm{~km}$ was obtained.

\subsection{Calibrations of the models}

Availability of observational soil moisture, LST, roughness $(\sigma / l)$ and bulk density data (SMEX03) have made it possible to perform model calibration as well as validation. The study regions are covered by 25 passive pixels and 88 ground sites. Among 75 observed passive pixels in 3 days, 60 pixels have been selected randomly as control points and the rest have been used as check points. Control points have been used for model calibration and coefficients estimation, while check points have been used for accuracy assessment.

Using the control points and least square method, the coefficients of the downscaling formula (equation 1) have been calculated. The result is shown in table 1 .

\subsection{Accuracy assessment of the models}

In order to obtain an estimate of overall accuracy of the models, it is necessary to use 3 days check points which have been excluded from the model calibration. The root mean square error (RMSE) of SM and LST retrieval based on the calibrated coefficients is presented in figure $3(\mathrm{a}, \mathrm{b})$, respectively. The errors of the SLPRM model in soil moisture and land surface temperature retrieval have been estimated around $3.9 \%$ and $2.8 \mathrm{~K}$, respectively.

Table 1. Coefficients of downscaling algorithm.

\begin{tabular}{llllllllll}
\hline$a_{0}$ & $a_{1}$ & $a_{2}$ & $a_{3}$ & $a_{4}$ & $a_{5}$ & $a_{6}$ & $a_{7}$ & $a_{8}$ & $a_{9}$ \\
\hline 20.04 & -6.42 & 3.74 & -26.13 & -5.13 & -1.29 & 5.70 & 127.80 & -45.92 & -15.17 \\
\hline
\end{tabular}




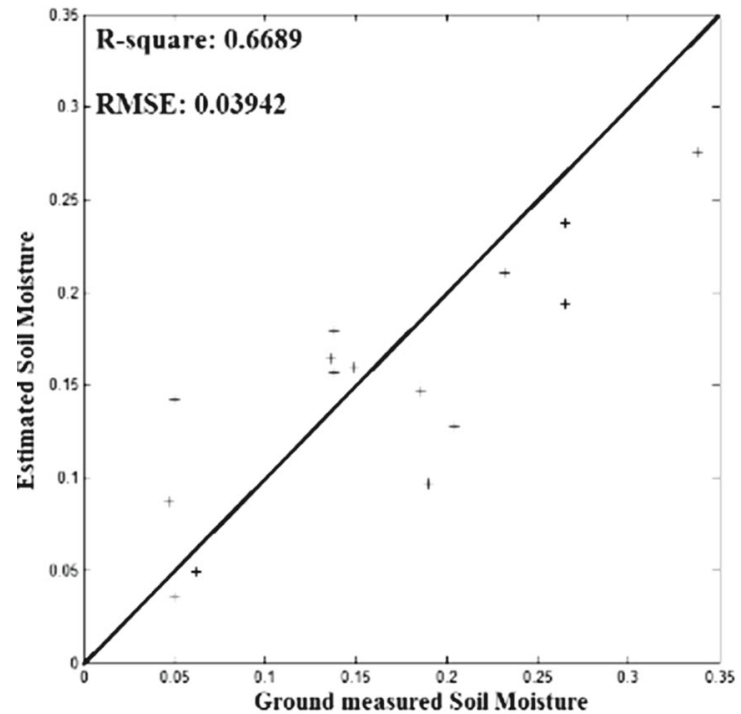

(a)

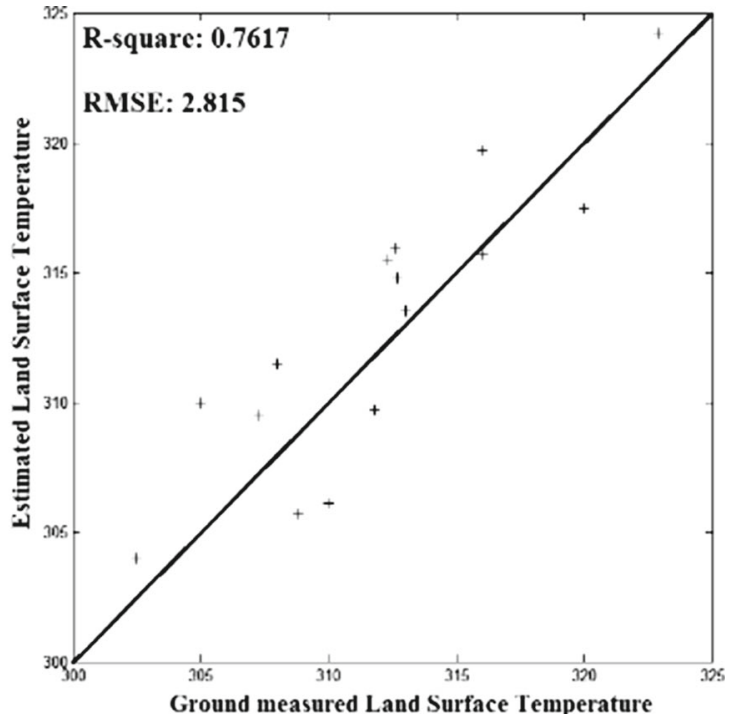

(b)

Figure 3. Comparison between measured and estimated parameters using SLPRM model. (a) Soil moisture and (b) land surface temperature.

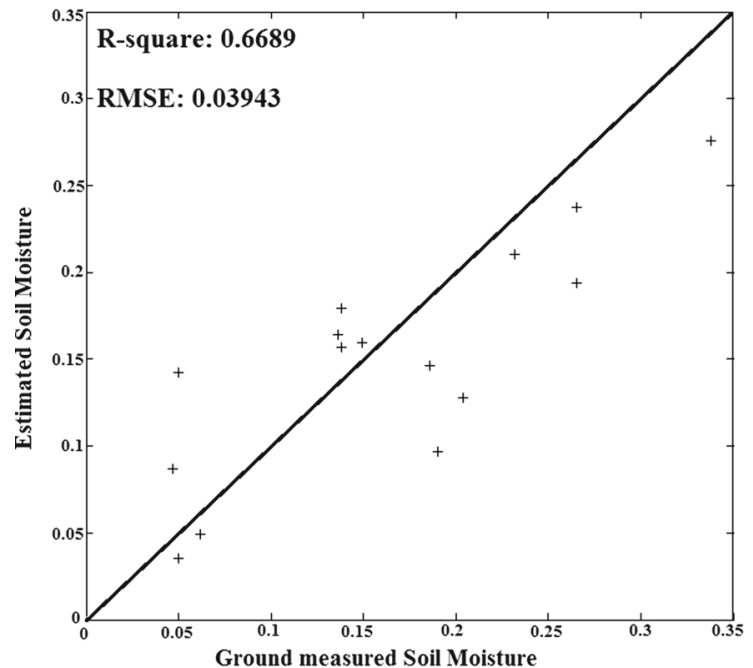

(a)

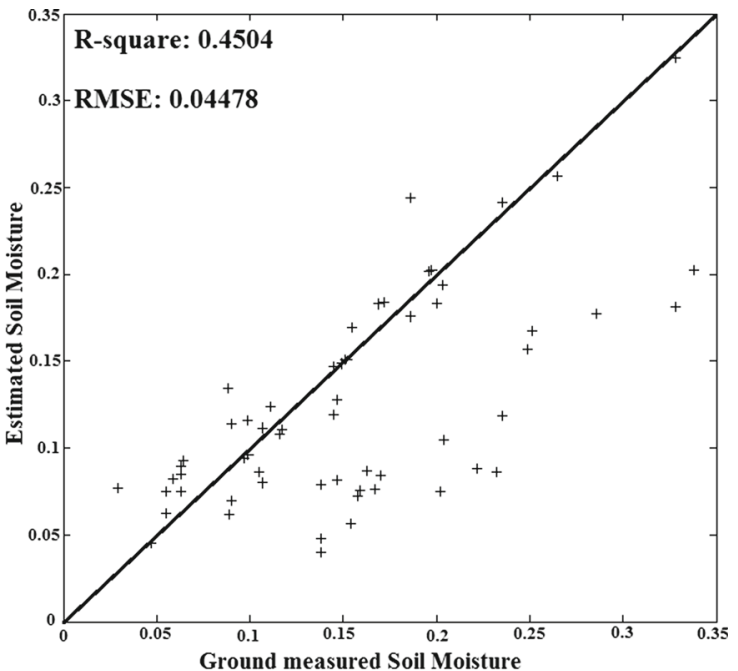

(b)

Figure 4. Accuracies of soil moisture retrieval using SLPRM model. (a) Before downscaling and (b) after downscaling.

Finally, retrieved VSM has been downscaled using equation (1) based on the calibrated coefficients shown in table 1. Comparison between the accuracies of soil moisture retrieval using SLPRM model before and after the downscaling is shown in figure 4 and table 2. As it was expected, there is a slight RMSE increase (about 0.5\%) in SM retrieval after downscaling, which means that proposed downscaling model is accurate.

Based on the results, either before or after downscaling, the SLPRM algorithm achieved acceptable accuracies.

Brightness temperatures at six frequencies (6.9, 10.7, 18.7 in $\mathrm{H}$ and $\mathrm{V}$ polarization) have been
Table 2. Comparison of soil moisture retrieval accuracy.

\begin{tabular}{ll}
\hline Methods RMSE $(\mathrm{SM}) /\left(\mathrm{m}^{3} / \mathrm{m}^{3}\right)$ & \\
\hline SLPRM algorithm before downscaling & 0.03947 \\
SLPRM algorithm after downscaling & 0.04478 \\
\hline
\end{tabular}

applied in equation (1) and according to the results, the $6.9 \mathrm{GHz}$ frequency in $\mathrm{H}$ polarization has shown the best operation compared to the others. Figure 5 shows the results of applying the downscaling algorithm to a derived soil moisture map over the ON for July 3, 2003. 


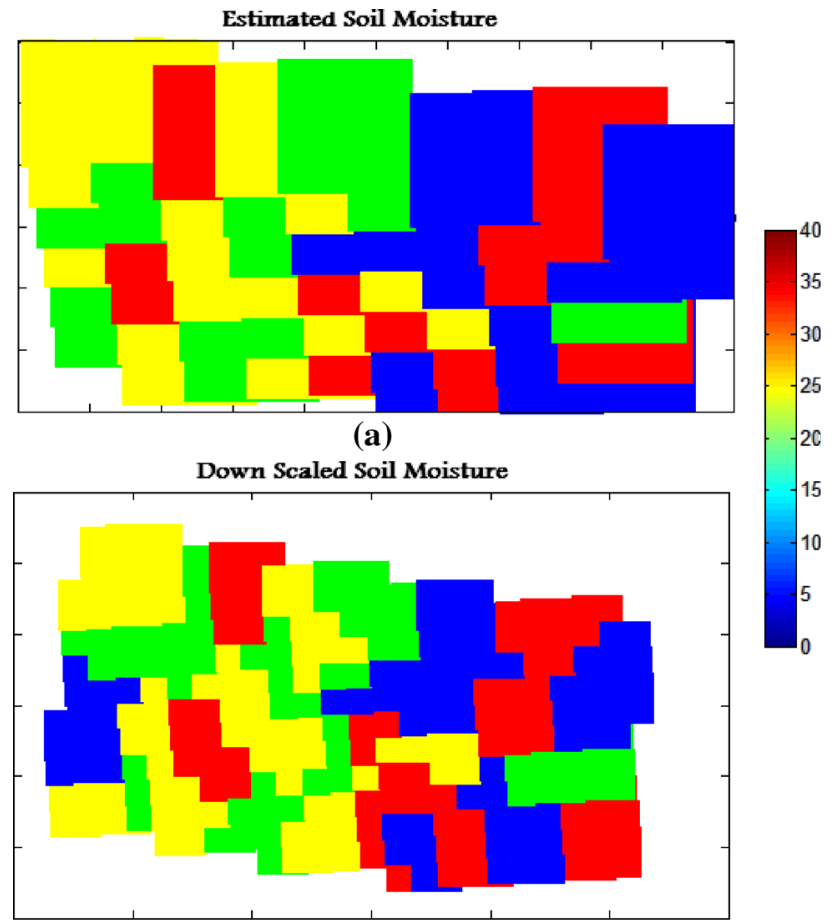

(b)

Figure 5. SM map over the Oklahoma, July 3, 2003. (a) Derived SM $\left(\mathrm{m}^{3} / \mathrm{m}^{3}\right)$ and $(\mathbf{b})$ downscaled $\mathrm{SM}\left(\mathrm{m}^{3} / \mathrm{m}^{3}\right)$ to $5 \mathrm{~km}$.

\section{Conclusions}

Due to the dependency of brightness temperature to soil surface roughness and vegetation cover, the SLPRM model has been developed based on considering the surface roughness effect on different vegetation density. The SLPRM method has been established based on the assumption of soil parameters interaction. Therefore, LST and canopy temperature are two parameters that have been estimated by the use of dual polarization and multichannel passive microwave measurements together with soil moisture simultaneously.

Furthermore, an algorithm for enhancing the spatial resolution of soil moisture, estimated from the SLPRM algorithm applied to AMSR-E data, using MODIS-derived NDVI and LST data has been presented. Results of the implementation indicate that downscaling is feasible to improve the spatial resolution of microwave accurate soil moisture retrievals. Accuracy assessment indicates that no significant degradation of the RMSE has been observed when moving into higher spatial resolution.
It should be noted that there are differences between satellite-derived parameters with the ground observations (in the nature of observation, acquisition times and vertical resolution) that should be considered in the accuracy assessment (Moradizadeh and Saradjian 2016).

The roughness has not been considered as one of the retrieval parameters in the SLPRM method, which might be regarded as shortcoming of the model. However, it is suggested that roughness is to be estimated using active microwave (SAR) images (Li et al. 2011), in addition to soil parameters estimation using brightness temperature of passive microwave data.

\section{Acknowledgements}

The authors thank the three anonymous reviewers for their comments, which have helped to improve this manuscript.

\section{References}

Allen P B and Naney J W 1991 Hydrology of the Little Washita RiverWatershed. Oklahoma: Data and Analyses; USDA, ARS-90, Washington, DC, 74p.

Carlson T 2007 An overview of the 'triangle method' for estimating surface evapotranspiration and soil moisture from satellite imagery; Sensors 7(8) 1612-1629.

Chanzy A and Wigneron J P 2000 Microwave emission from soil and vegetation; In: COST action 712 final report: Radiative transfer models for microwave radiometry (ed.) Mätzler C, Brussels, Belgium: European Commission (EUR 19543 EN), pp. 89-103.

Colliander A, Chan S, Kim S B, Das N, Yueh S, Cosh M, Bindlish R, Jackson T and Njoku E 2012 Long term analysis of PALS soil moisture campaign measurements for global soil moisture algorithm development; Remote Sens. Environ. 121 309-322.

De Lange R, Beck R, Van DeGiesen N, Friesen J, De Wit A and Wagner W 2008 Scatterometer-derived soil moisture calibrated for soil texture with a one dimensional waterflow model; IEEE Trans. Geosci. Remote 46(12) 40414049.

Dobson M C, Ulaby F T, Hallikainen M T and El-Rayes M A 1985 Microwave dielectric behavior of wet soil. Part II: Dielectric mixing models; IEEE Trans. Geosci. Remote $\mathbf{2 3}$ $35-46$.

Doubkova M, Van Dijk A I J M, Sabel D, Wagner W and Blöschl G 2012 Evaluation of the predicted error of the soil moisture retrieval from C-band SAR by comparison against modelled soil moisture estimates over Australia; Remote Sens. Environ. 120 188-196.

Gutman G and Ignatov A 1998 The derivation of the green vegetation fraction from NOAA/AVHRR data for use in numerical weather prediction models; Int. J. Remote Sens. 19(8) 1533-1543. 
Jackson T J and Schmugge T J 1991 Vegetation effects on the microwave emission of soils; Remote Sens. Environ. 36 203-212.

Jackson T J 1993 Measuring surface soil moisture using passive microwave remote sensing; Hydrol. Process. 7139 152.

Jackson T J, Bindlish R, Gasiewski A J, Stankov B, Klein M, Njoku E G, Bosch D, Coleman T L, Laymonand C A and Starks P 2005 Polarimetric Scanning Radiometer C- and $\mathrm{X}$-Band Microwave Observations During SMEX03; IEEE T. Geosci. Remote 43(11) 2418-2430.

Li Q, Zhong R, Huang J and Gong H 2011 Comparison of two retrieval methods with combined passive and active microwave remote sensing observations for soil moisture; Math. Comput. Model. 54 1181-1193.

Mo T, Schmugge T J and Wang J R 1987 Calculations of the microwave brightness temperature of rough soil surfaces: Bare field; IEEE T. Geosci. Remote 25 47-54.

Moradizadeh M and Saradjian M R 2016 The effect of roughness in simultaneously retrieval of land surface parameters. Phys. Chem. Earth. https://doi.org/10.1016/ j.pce.2016.03.006.

Moradizadeh M, Momeni M M and Saradjian M R 2013 Estimation and validation of atmospheric water vapor content using a MODIS NIR band ratio technique based on AIRS water vapor products; Arab. J. Geosci. 7 1891-1897.

Moradizadeh M, Momeni M and Saradjian M 2017 Assessment of the relationship between land surface temperature (LST) and near surface water vapor in central part of Iran; J. Geogr. Environ. Plan. 28(3) Ser No. 67.

Njoku E G 1995 Surface temperature estimation over land using satellite microwave radiometry; In: Passive microwave remote sensing of land-atmosphere interactions (eds) Choudhury B J, Kerr Y H, Njoku E G and Pampaloni P, VSP Publishing, Utrecht.

Njoku E G and Li L 1999 Retrieval of land surface parameters using passive microwave measurements at $6-18 \mathrm{GHz}$; IEEE Trans. Geosci. Remote 37 79-93.

Njoku E G, Jackson T J, Lakshmi V, Chan T K and Nghiem S V 2003 Soil moisture retrieval from AMSR-E; IEEE Trans. Geosci. Remote 41(2) 215-229.

Njoku E G and Chan S K 2006 Vegetation and surface roughness effects on AMSR-E land observations; Remote Sens. Environ. 100 190-199.

Owe M, Van de Griend A A and Chang A T C 1992 Surface moisture and satellite microwave observations in semiarid southern Africa; Water Resour. Res. 28 829-839.

Owe M, De Jeu R A M and Walker J 2001 A methodology for surface soil moisture and vegetation optical depth retrieval using the microwave polarization difference index; IEEE Trans. Geosci. Remote 39 1643-1654.

Pampaloni P and Paloscia S 1986 Microwave emission and plant water content: A comparison between field measurements and theory; IEEE Trans. Geosci. Remote $\mathbf{2 4}$ 900-905.

Pan M, Sahoo A K and Wood E F 2014 Improving soil moisture retrievals from a physically based radiative transfer model; Remote Sens. Environ. 140 130-140.

Patel P and Srivastava H S 2015 An approach to validate soil moisture derived from passive microwave sensors using SAR as an interface; Int. J. Remote Sens. 36(9) 23532374 .
Piles M, Camps A, Vall-llossera M, Sánchez N, MartínezFernández J, Monerris A, Baroncini-Turricchia G, PérezGutiérrez C, Aguasca A, Acevo R and Bosch-Lluís X 2010 Soil moisture downscaling activities at the REMEDHUS $\mathrm{Cal} / \mathrm{Val}$ site and its application to SMOS; Proc. 11th Spec. Meeting Microwave Radiometry Remote Sensing Environment 17-21.

Piles M, Camps A, Vall-llossera M, Corbella I, Panciera R, Rüdiger C, Kerr Y H and Walker J 2011 Downscaling SMOS-derived soil moisture using MODIS visible/infrared data; IEEE Trans. Geosci. Remote 49(9) 37-49.

Saradjian M R and Hosseini M 2011 Soil moisture estimation by using multi-polarization SAR image; Adv. Space Res. 48 278-286.

Schar C, Luthi D, Beyerle U and Heise E 1999 The soilprecipitation feedback: A process study with a regional climate model; J. Climate 12 722-741.

Schmugge T J 1985 Remote sensing of soil moisture; In: Hydrological forecasting (eds) Anderson M G and Burt T P, Wiley, New York.

Seneviratne S I, Luthi D, Litschi M and Schar C 2006 Land-atmosphere coupling and climate change in Europe; Nature 443(7108) 205-209.

Singh G, Srivastava H S, Mesapam S and Patel P 2015a Passive microwave remote sensing of soil moisture: A step-by-step detailed methodology using AMSR-E data over Indian sub-continent; Int. J. Adv. Remote Sens. GIS 04(1) 1045-1063.

Singh G, Srivastava H S, Mesapam S and Patel P 2015b Analysis of monthly soil moisture variations derived from AMSR-E for the year 2010 over Indian subcontinent; Proc. Int. Conf. Sustainable Energy and Build Environment, pp. 539-545.

Srivastava H S, Patel P, Sharma Y and Navalgund R R 2009 Large-area soil moisture estimation using multi-incidenceangle RADARSAT-1 SAR data; IEEE Trans. Geosci. Remote 47(8) 2528-2535.

Tsang L and Newton R W 1982 Microwave emission from soils with rough surfaces; J. Geophys. Res. 87 9017-9024.

Ulaby F T, Razani M and Dobson M C 1983 Effects of vegetation cover on the microwave radiometric sensitivity to soil moisture; IEEE T. Geosci. Remote 21 51-61.

Walker J P and Houser P R 2004 Requirements of a global near-surface soil moisture satellite mission: Accuracy, repeat time, and spatial resolution; Adv. Water Resour. 27(8) 785-801.

Wang X, Xie H, Guan H and Zhou X 2007 Different responses of MODIS-derived NDVI to root-zone soil moisture in semi-arid and humid regions; J. Hydrol. 340 12-24.

Wigneron J P, Chanzy A, Calvet J C and Brugier N 1995 A simple algorithm to retrieve soil moisture and vegetation biomass using passive microwave measurements over crop fields; Remote Sens. Environ. 51 331-341.

Wigneron J P, Kerr Y H, Waldteufel P, Saleh K, Escorihuela M J, Richaume M J, Ferrazzoli P, de Rosnay P, Gurney R, Calvet J C, Grant J P, Guglielmetti M, Hornbuckle B, Mätzler C, Pellarin T and Schwank M 2007 L-band Microwave Emission of the Biosphere (L-MEB) Model: Description and calibration against experimental data sets over crop fields; Remote Sens. Environ. 107 639-655. 
Zhang Y and Wegehenkel M 2006 Integration of MODIS data into a simple model for the spatial distributed simulation of soil water content and evapotranspiration; Remote Sens. Environ. 104(4) 393-408.
Zheng, J Y, Li Z, Chen Q and Bi H Y 2015 Method for soil moisture and surface temperature estimation in the Tibetan Plateau using space borne radiometer observations; IEEE Geosci. Remote Sens. Lett. 12(1) 97-105.

Corresponding editor: D SHANKAR 